\title{
Emerging trends in regional science
}

\author{
Antoine S. Bailly ${ }^{1}$ - Lay James Gibson ${ }^{2}$
}

Published online: 10 April 2017

(C) The Japan Section of the Regional Science Association International 2017

\begin{abstract}
Regional science has been evolving as a discipline since the 1950s. Whereas it has a distinctive focus and personality, it has not evolved in isolation. We recognize the early influences of economics and geography and other social and natural sciences. But we also recognize emerging trends that regional science can benefit from as it matures. In this paper we discuss emerging academic influences and critical research themes that have the ability to further shape regional science as a useful discipline for solving real-world problems.
\end{abstract}

Keywords Big data $\cdot$ Geographic information systems $\cdot$ Medicometry $\cdot$ Metadata Milieu theory - Transdisciplinarity

\section{Introduction}

With almost no advanced notice, regional science's founder, Walter Isard could make a convincing presentation on the academic influences that have shaped regional science. If he were visiting a department of sociology he might title his presentation "Sociology's Contributions to Regional Science," for a department of psychology it would be "Psychology's Contributions to Regional Science." Isard was so well read and thoughtful that he could do a convincing job with the contributions of economics, geography, environmental science, planning and just about any other discipline, multidisciplinary field or professional field. This skill

Lay James Gibson

ljgibson@comcast.net

Antoine S. Bailly

Antoine.Bailly@unige.ch

1 University of Geneva, Geneva, Switzerland

2 University of Arizona, Tucson, USA 
made him welcome and at home in a variety of settings - making a presentation to a group of undergraduate students at the University of Geneva, to a group of colleagues at the British-Irish Section of the Regional Science Association International, or when speaking to development professionals somewhere in the Asia-Pacific realm. It also made him a powerful advocate for regional science. He in one presentation could make regional science something universal and at the same time a discipline tied to all, or at least many, other disciplines.

Professor Isard is now gone but his legacy lives on. We are certain that if Professor Isard were still alive he would be the first to encourage regional scientists to track developments in disciplines and fields that complement the emerging discipline of regional science. Professor Isard also had good instincts when it came to recognizing emerging research themes and when it came to positioning regional science at the front of the pack of disciplines prepared to contribute to the understanding of emerging research themes. An example was his 1973 book on Ecologic-economic Analysis for Regional Development: some Initial Explorations with Particular Reference to Recreational Resource Use and Environmental Planning. This book (Isard et al. 1973) tied regional science to environmental impact analysis and environmental planning-fields that were emerging but certainly on the fringe in the days prior to environmental quality legislation.

In this paper we will explore a handful of disciplinary and professional developments that have important implications for the way that regional science is practiced today. We will also consider some critical research themes that are certainly not the exclusive turf of regional science but are themes that can clearly benefit from the perspectives and approaches that regional science offers.

Our intention is not to provide a comprehensive review of the research themes followed by regional scientists during the last one-half century. Mulligan (2014) did a superlative job of this in his recent comprehensive review of regional science. Our goal is to encourage regional science to continue exploring ways of contributing to the solutions of critical problems facing scientists, public policy leaders, and private decision makers.

\section{Emerging academic influences and critical research themes}

Professor Walter Isard set the stage for ongoing discussions of academic influences and critical research themes in his early work. In Location and the Space Economy, Isard (1956) took the position that regional science focuses on economic themes inasmuch as economics is the most highly developed of the social sciences but as regional science matures it will increasingly look to geography, sociology, political science, and environmental science. This was certainly the motivation for his "contributions" presentations and for much of his written work including Methods of Regional Science (1960) and Ecologic-economic Analysis for Regional Analysis (1973) where he took regional science into physical geography and the natural sciences. He also made a strong case for regional science's usefulness for environmental science planning. 
By the early 1970s regional science was well established. Further, it was clear that regional science would grow and evolve by continuing to borrow useful concepts and approaches from other disciplines and fields. In the years since 1970 other fields have emerged that appear to have a great deal to offer regional science as it goes forward. In the spirit of Professor Isard's "contributions to..." we have identified three fields that we think have the potential to continue to contribute to regional science as both a theoretical discipline and as an applied science. Our three selections are certainly not the only three but they can certainly make regional science more versatile. In the discussion that follows we will deal with management, GIS, and human ecology as fields that have a great deal to offer regional science as it continues to evolve.

\section{Management}

Both private and public management have grown in popularity on university campuses during the past 50 years. Some may argue that private and public management have partially replaced the social and behavioral sciences by taking social and behavioral science theory and applying it to real-world problems in an environment that offers professional and financial rewards for solving critical problems. In our recent paper Securing the Future of Regional Science Conditions for a Core Discipline (Bailly and Gibson 2015) we argue that the future of regional science will be brighter if regional science opens itself to more extramurally funded research and to more applied research in the private, public and NGO sectors.

\section{Regional management}

Management in the traditional sense is certainly something important, especially in the area of "regional management." Management as the term is used here is a collective action in a region. It is a developing field that often focuses on subnational regions and some might argue is a key for sustainable growth. Far from Taylor's rational management, new management is based on participation and collaboration. One good example is "milieu theory" developed by Camagni and Maillat (2006); all regional stakeholders work together to improve information, know-how, and innovation; "milieu theory" has been employed with positive results in Italy and Switzerland. It appears that the theory works best when there is a common culture and goals.

During the recent world economic crisis many countries including several in Europe were in recession. But as Paul Krugman (2008) said, regional crises were often more important than the national crisis. Some regions are becoming poorer than their national economies, especially in cases were growth was driven or led by metropolitan regions. Lagging regions need to see their economic base renewed if they are to stay competitive and this requires that all actors-economic, social, political, and education-work together proactively and prior to eventual trickle down impacts from metropolitan or other more robust regions. This is why in 2014 a 
new programming period started for the E.U. under the Directorate for Regional and Urban Policy with a cohesion policy to prevent regional disparities.

The notion of lagging regions is initially economic but the political implications and the implications for regional management are substantial. In Europe, for example, lagging regions are numerous. In some cases they discuss going their own way. It is worth considering the implications for an efficient E.U. policy for regional management. An important question for the E.U. is what are the management implications for a union that once had 28 entities that has now ballooned to over 60 entities. This is always an interesting hypothetical but in a world where increased migration from the Middle East and Africa with its cultural conflict and where failed economies are increasingly common it is easy to conclude that regional management is a requirement if crises are to be avoided or at least minimized.

\section{Geographic information systems}

Geographic information systems and the even broader area of geoinformatics have been around for decades but have taken on new significance as technology has been developed to manage and display increasingly large data sets. The applications of Big Data to regional science are almost infinite. It is easy to imagine applications for planning, demography, trade area analysis, etc. A long-standing debate asks the question, is GIS simply a technique or is it a substantive field? It is easy to see regional scientists coming down on both sides of this debate. Skilled technicians with an interest in regional science applications might find themselves enhancing and expanding the application capabilities of a specific GIS whereas regional scientists coming from backgrounds in geography, economics, sociology and other disciplines might favor more substantive applications. In any case this is a field that has roots in geography, land planning, computer science, and many other fields (Getis 2004a, b). It was in its infancy during the early days of regional science but has now grown to a mammoth and complex enterprise that deserves to be part of the skill set that regional science brings to the table. It is one of the goals of regional econometrics to improve the quality of the models to be applied at the regional levels.

The problems associated with managing spatial data have always been substantial but were made even more challenging with expanded developments in the remote sensing of data. Now with an increasing emphasis on "big data" and on "metadata" the importance of being technically conversant with GIS is even more clear. Less clear is the question of whether regional scientist should be on the cutting edge of GIS or simply literate users of GIS technology.

\section{Human ecology}

Human ecology is a natural field of interest for regional scientists. It explores the relationship between humans and their cultural (social, political, and economic), natural, and built environments. It is interesting to speculate about the contributions 
that have already been made to regional science by human ecologists and geographers such as P. Haggett. But it is worth considering the future contributions that could be made by human ecology in terms of relations between people of different cultures.

Regional science's relationships with disciplines and professional fields with a humanistic bent appears to be friendly but less robustly developed than relationships with more quantitatively based sciences including economics and geography and professional fields like urban and regional planning. There are a variety of avenues for regional scientists to be drawn closer to human ecology and one avenue is a shared interest in the growth and development of urban spaces. Architects and planners who often find themselves based in the same university units or in civic or corporate units have an obvious interest in different aspects of human ecology and sharing responsibility for assignments with a human ecology perspective. Many departments of geography now include human ecology as a basic field-some even use the words "human ecology" in the title of the department.

\section{Critical research themes}

Any discussion of critical research themes will be a mix of themes of enduring importance and themes that are of current significance that will fade as time passes. Many will eventually be replaced by another "flavor of the day."

Having said this we will mention a handful of items that might be explored, or further explored, that would help to remind scholars, business leaders, and policy makers that regional science is of enormous value in understanding critical issues and of great utility when it comes to managing and solving problems that face regions, governments, and businesses.

\section{International migrations}

This has been a major issue for years for many regions of the world. Sometimes the distances are modest, e.g., the movement of people across the southern border of the US from Mexico or the movement of people from North Africa to Europe. In other cases the distances are much greater, e.g., the movement of people from Central Africa or South Asia to Europe. But in any case there are huge repercussions for both sending and receiving areas. Both the motivations and the repercussions can be economic, social, or certainly cultural. Regional scientists are concerned with the content of regions and they are also concerned with flows and linkages. Regional science is well positioned to respond to a situation where there is heightened public awareness and to one where there is a critical need for policies that will help manage the flows themselves and the sociocultural and economic ramifications of these flows. The E.U. is asking for proposals to manage more and more immigration in different regions and countries. Are regional scientists prepared for the challenge? 


\section{Climate change}

Most regional scientists have neither the training nor the inclination to be involved with measuring the environmental factors that produce climate change but they are well positioned to consider the economic and sociocultural costs and benefits of climate change including premature articulation of remediation strategies. Many politicians are willing to uncritically assume that man-caused climate change is real, significant, accurately measured and fairly easily managed. Serious scientists are less confident. Natural scientists will continue to debate the measurement of climate change, its sources, and its significance. But even before these issues are better understood and more fully resolved regional science can contribute to discussions of a variety of topics such as the costs and benefits of national climate policies, the implications of climate change on food production systems, tourism, and the costs and benefits of alternative energy sources. Questions of these sorts typically have both a local dimension and a global dimension; regional scientists are typically comfortable working at different geographic scales and might be expected to weighin.

\section{Health care}

Regional scientists have certainly contributed to discussions on this topic but there is clearly still work to be done. Regional scientists have made contributions in the area of epidemiology including research on the spread and management of pandemics. They have also done innovative work on the delivery of health care in remote and under-served areas developing the concepts of health basins. Again, regional scientists are not bio or physical scientists (usually) producing pharmaceuticals nor are they the direct providers of medical services but they do contribute to the understanding of efficient delivery of health care services.

A significant example of regional scientists and health care professionals working together to form a new transdisciplinary field is the case of medicometry. In the 1980s regional scientist Antoine Bailly, medical doctor Michel Periat and a handful of others came together to form a working group committed to using regional science approaches to solve health care delivery problems (Bailly and Periat 1995). The idea was to develop a new transdisciplinary field that would go beyond the scientific synergy of specialized fields by developing a more global understanding of health issues - the medical, sociological, geographical, ecological, and economic factors that combine to provide a global view of health and health care in a regional society. Initially the focus was on Switzerland, often the peripheral portions of Switzerland. But since the 1980s the scope of studies has changed substantially to include a more international focus on the location of health care facilities, hospitals and health care centers in villages. Studies also include the movement of health care professionals between countries, and the consequences of such movements.

Health care is increasingly recognized as a critical element in both advanced and lagging regions (Morrison et al. 1998). The expectation is that regional scientists 
will increasingly embrace a medicometry approach when attacking complex health care problems (Getis 2004a, b; Getis and Ord 1998). Such a strategy seems consistent with Isard's (1960) broad definition of regional science as an interdisciplinary field that examines the locational dimensions of all human activities relevant to society including economic, political, social institutions.

Unfortunately, research by Bailly and Coffey (1994) suggests that research that actually fits this broad definition of regional science is not as abundant as hoped. Instead the increasing specialization and fragmentation of sciences is responsible for this trend towards a "chaos of disciplines" (Abbott 2001). Regional science, like many disciplines, is shaped by Newtonian views of the world, a physical rationale lacking an integrating system of knowledge. We need now to consider the challenge of the integration of sciences by transdisciplinarity-by changing regional science from a science of regional location to a science of more broadly based regional societies.

\section{Transdisciplinarity}

In his book Chaos of disciplines, Abbott (2001) writes about the almost overwhelming challenges of articulating new disciplines, analytical perspectives and collections of metadata. In some ways there is a tendency to want to specialize but complexity of issues and of data management suggests that the global issues that are increasingly being faced require more comprehensive approaches. It might be argued that the notion of transdisciplinarity is a response to these changing demands. It can also be argued that there is a sense of urgency pushing the acceptance of transdisciplinarity; the urgency comes from applied scientists faced with critical issues of environmental pollution, resource use and human migrations.

Transdisciplinarity is interesting because of the scientific questions that are implicit but also because of the strong implications for practitioners who have a need for effective ways of addressing questions of client-driven applied research. In a recent paper (2015) we emphasize the role of applied regional science, as a driver for new global approaches.

Transdisciplinarity extends beyond mere interdisciplinarity by its focus on dealing with real-world questions. As Sholz and Steiner write, outcomes must be useful to both practice and science, to contribute to a better understanding of the real world (Sholz and Steiner 2015). They offer examples of world challenges, such as pollution, social injustice, migration, and resource use-themes which are fairly common in the literature of regional science (Sholz and Steiner 2015).

When medicometry was developed in the 1980s it was intended to be a new transdisciplinary field that would go beyond the constraints and scientific synergy of specialized fields by offering a more global understanding of health care, an understanding that integrated economic and cultural dimensions, technical practices, even governance actions and policies on regional populations. Today we have a new player with the much same goal. The Regional Science Academy that is being championed by Nijkamp and Kourtit deals with big and complex challenges. The value added by the proposed Academy comes with the development of the 
foundations for an integrated regional theory and methodology (Nijkamp and Kourtit 2016).

\section{Some concluding thoughts}

Regional science should continue to track developments in other disciplines and adopt them as appropriate. In this paper we identify three emerging disciplines that have, or probably should, strong and positive influences on regional science much the same way as economics and geography had strong influences in the 1950s and 1960s.

We do not suggest that the three that we name are the only three with something to offer but we do think that a good case can be built for putting them at the top of the list.

A business school discipline with much to offer is management. Given the need to make regional science an important problem-solving discipline, management is essential to regional science thinking to help assure that project findings and recommendations are implementation oriented. A useful example of this is regional management as discussed by Camagni and Maillat (2006). A second discipline is geographic information systems. We acknowledge that some would dispute the status of GIS as a discipline but given its current status and potentials for dealing with metadata and big data we are willing to accept GIS into the fraternity of useful disciplines.

A third discipline that can be more aggressively aligned with regional science is human ecology. This would give regional science a more humanistic dimension and complement the relationship that can exist between architecture, planning and regional science.

We realize that the business of picking "hot topics" for research has mostly short-term benefits but we do assert that selecting high visibility themes can help to raise regional science's reputation as a powerful problem-solving discipline.

International migrations are nothing new but there is a heightened awareness of this issue and it is well suited to regional science approaches. Policy makers in Europe and North American and in other regions too have an urgent need to understand the economic, social and cultural impacts of large-scale movements of people on both sending and receiving regions. A second area that could benefit from increased attention by regional scientists is climate change. Climate scientists will continue to debate the science of measuring climate change but there is important work for regional scientists when it comes to evaluating the impact of these changes on social, economic, and political systems. Estimating the costs and benefits that might come with climate change is clearly work that regional scientists are well suited to undertake.

Third we consider the broad theme of health care. In this discussion we focus on two specific items: medicometry and transdisciplinarity. Medicometry is a fairly new interdisciplinary field which was developed by health care professionals and regional scientists to solve health care delivery problems. Transdisciplinarity is evolving as a more comprehensive and complex way of thinking of interdisciplinary 
problems which have a real-world and applied science focus. It is possible that transdisciplinarity could become the new foundation for a more complex and more fully integrated "regional science" of health care.

\section{References}

Abbott A (2001) Chaos of disciplines. University of Chicago Press, Chicago

Bailly A, Coffey W (1994) Regional science in crisis. Pap Reg Sci 73(1):3-14

Bailly A, Gibson LJ (2015) Securing the future of regional science: conditions for a core discipline. Stud Reg Sci 45(2):119-125

Bailly A, Periat M (1995) Médicométrie. Economica, Paris

Camagni R, Maillat D (2006) Milieux innovateurs. Economica, Paris

Getis A (2004a) A geographic approach to identifying disease clusters. In: Janelle DG et al (eds) Geographical perspectives on 100 problems. Kluwer, Dordrecht, pp 81-86

Getis A (2004b) The role of geographic information sciences in applied geography. In: Bailly A, Gibson LJ (eds) Applied geography: a world perspective. Kluwer Acad. Publ., Dordrecht, pp 95-112

Getis A, Ord JK (1998) Spatial modeling of disease dispersion using local statistics: the case of AIDS. In: Griffith DA, Amrhein CG, Huriot JM (eds) Econometric advances in spatial modelling and methodology. Essays in honour of Jean Paelinck. Kluwer, Dordrecht, pp 143-158

Isard W (1956) Location and space economy. The MIT Press, Cambridge Mass

Isard W (1960) Methods of regional analysis. The MIT Press, Cambridge Mass

Isard W et al (1973) Ecologic-economic analysis for regional development: some initial explorations with particular reference to recreational resource use and environmental planning. The Free Press, New York

Krugman P (2008) The return of depression economics and the crisis. Times Columns, New York

Morrison AC et al (1998) Exploratory space-time analysis of reported cases during an outbreak in dengue cases during an outbreak in Florida, Puerto Rico, 1991-1992. Am J Trop Med Hyg 58:287-298

Mulligan G (2014) Regional science at sixty: traditional topics and new directions. Australian J Reg Sci 20(1):4-67

Nijkamp P, Kourtit K (2016) Towards a Regional science academy: a manifesto. Reg J ERSA. 3/1 [online]. doi:10.18335/region.v3i1.120. (Mimeograph, Doc. 1.2)

Sholz RW, Steiner G (2015) Transdisciplinarity at the crossroads. Sustain Sci 10(4):521-526. doi:10. 1007/s11625-015-0338-0 